\title{
Innovation and Personality: A Study of Attitude to Innovation among Krasnoyarsk Students and Business Experts using the Basadur-Hausdorff Method
}

\author{
Maria I. Ilbeykina \\ Maria A. Kolesnik \\ Natalia M. Libakova \\ Ekaterina A. Sertakova \\ Alexandra A. Sitnikova* \\ Siberian Federal University, Russian Federation; *Corresponding Email: sitnikova_aa@inbox.ru
}

Doi:10.5901/mjss.2015.v6n6s7p282

\begin{abstract}
There is a fair amount of demand for research into innovation and its role in a modern person's life. Readiness for change and innovation is a sign that a society follows the path of progress. It also allows one to make predictions regarding that society's development. This paper is an attempt to study people's attitudes to innovation. It was conducted within the city of Krasnoyarsk using a method designed by M. Basadur and P. Haudsorf, creators of a recognized scale for measuring an individual's attitude to innovation. The paper includes a detailed description of the method itself and gives an overview of relevant literature. The study is based on responses provided by various Humanities students from the Siberian Federal University and experts from the Krasnoyarsk City Innovation and Technology Business Incubator. The respondents were given a questionnaire comprising 24 questions and allowing researchers to gauge the Krasnoyarsk community's overall perception of creativity, predisposition to innovation, and attitude to new ideas in their immediate areas of activity. The results were distributed across four scales, which revealed a positive attitude to innovation and a readiness to embrace it in both respondent groups. Respondents from the Business Incubator sent a clear message that new ideas must be put into practice. They also strongly supported boosting creativity on a personal level so as to help promote a highly developed society. Student respondents were fully in tune with Krasnoyarsk business experts and in addition revealed high potential for developing and implementing innovation.
\end{abstract}

Keywords: innovation, creativity, Basadur-Hausdorf methodology, innovative thinking, Siberian Federal University

\section{Introduction}

In the modern hi-tech day and age, anything to do with innovation is bound to generate plenty of demand and good prospects. Studies of various aspects of innovation, their essence and practical implementation, and research into boosting innovative personal qualities, are in demand in a whole range of areas, from technology and economics to politics and even society and culture. These days, researchers tend to look beyond justthe practical aspects of implementing innovation and developing personal creativity: they also focus on analyzing people's attitudes to innovation and any related issues.

This paper presents the results of our study of people's attitudes to innovation. The study is conducted using a method designed by M. Basadur and Peter A. Hausdorf (1996). It incorporated responses from business experts working at the Krasnoyarsk City Innovation and Technology Business Incubator, an organization helping young local entrepreneurs to launch and promote their startups so as to make Krasnoyarsk a more business-friendly place. The Business Incubator was chosen thanks to being one of the leaders in implementing innovation, working to promote innovation in the region. The second group of respondents included 1st to 4th year Humanities students pursuing a bachelor degree at the Siberian Federal University in one of the following fields: Cultural Studies; Arts and Humanities: Cinema and Video; Religious Studies; Advertising and Public Relations; Philology; and Linguistics.

Humanities students were chosen for a reason. To begin with, students are future experts who one way or another will be participating in the process of implementing innovation in a whole range of areas. On top of this, we decided to focus on humanities because, unlike technology studies, they are not perceivedas high-priority areas and are excluded 
from the group of vital, promising, and innovative fields supported by the government.

The paper includes comparative analysis of questionnaire results from the two groups: business experts (that is, hands-on practical thinkers working closely with innovation) and humanities students who are traditionally seen as people who have very little to do with innovation.

\section{Literature Review}

Concepts such as 'innovation' and 'innovative person' are popular subjects in both domestic and Western research. An attempt to comprehend this phenomenon at the scientific and theoretical level by turning to research publications will reveal a wide range of aspects and attitudes. For example, papers on innovation and its role in an individual's life can be split into several self-sufficient groups.

A fair number of publications attempt to define the concept of 'innovation' and specify its characteristics. Researchers working in this area (Sawhney et al., 2006; Glor, 2015a; Glor, 2015b, Van de Ven, 1986; Drejer, 2004) suggest defining innovation in a narrow and a broad sense, that is, as developing something new or improving on something that already exists. When addressing this issue though, researchers most often focus on technological innovation (Teece, 1996; Sood and Tellis, 2005; Ahuja, 2000; Garcia et al., 2002; Prajogo, 2006; Moskvin, 2008; Kirko et al., 2012; Koptseva et al.; 2014a, 2014b; Sevastyanova, 2015 etc).

There is a second group of sources dealing with the problems of classifying innovation. The most popular types of innovation one can come by in research publications are 'evolutionary' and 'revolutionary' (Tushman et al., 1986); 'group' and 'individual' (Janssenet al., 2004); and 'global' and 'specific' (Goldsmith, 1984; Goldsmith et al., 1991, ). These sources too are more inclined to view innovation from the economic perspective (Kirko et al., 2013; Koptseva, 2014; Kistova et al., 2014; Lenskaya, 2014, etc). But the literature we have reviewed also revealed a steadily increasing amount of social, psychological, and cultural research in the area of innovation. This indicates the growing role of creating and consuming original ideas in overall social development and in personal identity formation.

The third group deals with research into personal innovation. Here many authors talk about the link between personal innovative disposition and cultural factors and axiological meanings. This approach is particularly favored in works and papers analyzing personal innovativeness from a cross-cultural perspective (Shane, 1995; Smith et al., 2002; Dollinger et al., 2007; Steel et al., 2012; Lebedeva, 2008, 2009, 2011; Ilbeykina et al., 2015).). A sufficiently reliable set of tools was developed for rating the cultural values affecting a society's level of innovativeness (Kirton \& De Ciantis, 1986; Schwartz 2006; Moskvich et al., 2011; Zhang, 2015, etc).) The fourth and the smallest group of studies are aimed at identifying people's attitudes to innovation. These works are well indem and since gauging society's attitude to innovation is important for integrating innovation into various areas of human activity. Data generated through this research can shed light on whether introducing innovation will be effective, whether any preparatory work is required or whether the efforts are grinding to a halt. Researchers (Kharkhurin et al., 2008; Baer et al., 2006; Anoshkina et al., 2001; Bogomaz et al., 2007; Dolgova, 2013; Klochko et al., 2009; Wu et al.,2014).) point out the importance of identifying and promoting innovative thinking in individuals. In this connection, one can single out a group of studies dedicated specifically to stimulating innovative thinking among the indigenous peoples of Siberia and the North (Koptseva et al., 2014b; Libakova et al., 2014; Zamarayeva, et al., 2015 etc.)

Reliable methods of gauging people's attitudes to innovation are very scarce. Some of the most prominent examples in Russia include works by N. M. Lebedeva and A. N. Tatarko (2009). Their questionnaires in many ways draw inspiration from foreign researchers, such as M. Kirton, author of the 1976 Adaptation-Innovation scale, M. Basadur and P. Hausdorf, authors of the 1993 scale for measuring attitudes to creativity. We found the latter approach most relevant to the purposes of this research.

To sum it up, the sources available to date tend to focus on various aspects of innovation, particularly technological. These works greatly out number psychological and cultural studies, which only adds to the relevance of this paper.

\section{Research Methodology}

The research was carried out in April 2015 in Krasnoyarsk city by the scientists of cultural studies department of Siberian Federal University. To test whether Krasnoyarsk business experts and Siberian Federal University humanities students are prone to innovative thinking, we turned to psycho diagnostic surveying, a method described by M. Basadur and Peter A. Hausdorfin (1996) in their publication, Measuring divergent thinking attitudes related to creative problem solving and innovation management. Their article suggests that the first step in integrating creative technologies into business is 
to test whether relevant employees and students are ready to embrace creative and innovative thinking. Once the questionnaires are completed, the findings are used in the following way: more creatively inclined employees are immediately invited to get involved in relevant innovative activities within the organization, whereas less creatively inclined employees are referred to special classes to stimulate their creative thinking.

The first version of the psycho diagnostic innovativeness questionnaire was designed in 1985 and included 14 statements aimed at revealing whether respondents were creatively inclined, from two perspectives: 1) valuing new ideas (that is, understanding that development requires generating new ideas) and 2) believing (or not) that creative thinking is bizarre and eccentric. Believing that creative thinking is eccentric is, in fact, a stereotype that prevents people building rational mechanisms to help them think creatively. Respondents would rate the statements in a fairly traditional way by marking them on a scale from 1 to 5 from "completely disagree" to "completely agree".

In 1996 the psycho diagnostic questionnaire was expanded to 24 statements, and two more factors were added: 3) preference for ideas (that is, preferring ideas over actions; the authors do admit that this point is quite close to the first perspective, but they also believe there is scope for two separate factors); 4) "too busy for new ideas" (a number of statements are clearly aimed at identifying people who are unable to embrace creative thinking because they overprioritize work and the daily grind).

Quoted below is the final list of statements recommended by the questionnaire authors (the factor revealed by each of the statements is indicated in brackets; also, to ensure that answers are valid and respondents did not tick them off mechanically, some statements are phrased in such a way that answers to them would need to be reversed: such questions are marked with an "R" in brackets):

1. I often come up with new ideas based on ideas by other people. (3)

2. I get the impression that creative people have a bizarre and irrational way of thinking.(2)

3. Ideas are fundamental for decision-making and should not be taken for granted. (1)

4. New ideas appear only rarely. (3; R);

5. Most people never get to use their mind's full potential when working on a problem. (3)

6. Truly creative people always lead an unusual lifestyle. (2)

7. Company management should encourage innovative ideas by demonstrating readiness to incorporate them. (1)

8. I often feel embarrassed to suggest my wild/crazy ideas. People laugh at me and doubt that I can think sensibly. (3)

9. I am really happy when I am challenged to find a new way to solve a problem. (3)

10. Truly creative people are never organized. (2)

11. Some people really amaze me with their innovative ideas. (3)

12. I do not have enough time to come up with wild/crazy ideas. I am already too busy trying to cope with my dayto-day tasks. (4)

13. Most innovation happens out of necessity or to solve a current issue. (3)

14. Why all this buzz about ideas? I already have more current tasks that I can cope with. (4)

15. I feel excited when I come up with a new idea. (3)

16. Ideas are important only if they have an effect on a far-reaching large-scale project.(4)

17. Everyone comes up with creative ideas from time-to-time. (3)

18. Boss'/Manager's ideas are always the best because they have a broader outlook behind them. $(1 ; R)$

19. Ideas that sound crazy may turn out to be useful. (3)

20. Listening to other people's ideas is a waste of time. $(3 ; \mathrm{R})$

21. Productive changes are important for business. New ideas stimulate change. This is why new ideas are important for business. (1)

22. If everyone is busy promoting ideas, there will be nobody to do the work. (4)

23. The more problems I have, the more opportunities arise. (3)

24. Only the most intelligent and educated people can generate good ideas. $(3 ; \mathrm{R})$

Based on this method, we were able to conduct our study and analyze whether humanities students from the Siberian Federal University and experts from the Krasnoyarsk City Innovation and Technology Business Incubator are inclined to think innovatively. We then compared the results from the two groups to estimate how easily students could integrate with the city's business environment. The 1996 article suggested that results must be calculated using Cronbach's alpha, but these days many studies in social sciences, including psycho diagnostic innovation research, back the idea that calculating the arithmetic mean can be a sufficient and fairly reliable way to process the results and bring more clarity to the task of interpreting them (Volobueva, 2012, p. 39-44). 


\section{Findings and Discussion}

A total of 135 respondents participated in the study, including 35 business experts from the Krasnoyarsk City Innovation and Technology Business Incubator (32 out of these 35 questionnaires made it to the final stage once we eliminated in complete submissions) and 100 Humanities students from the Siberian Federal University pursuing Cultural Studies; Arts and Humanities: Cinema and Video; Religious Studies; Advertising and Public Relations; Philology; and Linguistics (93 of their questionnaires were processed once incomplete submissions were eliminated).

Following the guidelines proposed by M. Basadur and Peter A. Hausdorf, the respondents were asked to mark 24 statements, and the resulting data was distributed across the four scales designed by the method authors, each revealing a particular aspect of a respondent's attitude to new ideas and creativity-related stereotypes in general, as well as the place they assign to new ideas in their own lives.

Table 1. Results from the business community

\begin{tabular}{lccccc}
\hline & $\begin{array}{c}\text { Completely } \\
\text { agree }\end{array}$ & $\begin{array}{c}\text { Rather } \\
\text { agree }\end{array}$ & $\begin{array}{c}\text { Not } \\
\text { sure }\end{array}$ & $\begin{array}{c}\text { Rather } \\
\text { disagree }\end{array}$ & $\begin{array}{c}\text { Completely } \\
\text { disagree }\end{array}$ \\
\hline Understanding the value of new ideas & 7.08 & 12.08 & 4.2 & 6.92 & 2.92 \\
Personal stereotypes regarding creativity & 1.7 & 7.3 & 4.3 & 14 & 4.7 \\
Valuing new ideas for business & 9.5 & 14.2 & 5.5 & 3 & 1 \\
Too busy for new ideas & 1.5 & 7 & 4.2 & 14 & 5 \\
\hline
\end{tabular}

Answers to the statements pertaining to the first scale suggest that experts from the Business Incubator are quite opinionated when it comes to new ideas: only a small number of respondents were not sure about their position. At the same time, most respondents agreed that new ideas are a valuable asset required for development, but a large number of them also disagreed with this statement. Understanding the value of new ideas is a fundamental scale for identifying people capable of appreciating innovation, which is why it is utterly strange to see nearly a third of the Business Incubator experts being skeptical about generating new ideas, given that their job is closely connected with discovering new startups, that is, inevitably, products of ideation.

The statements pertaining to this scale revealed that business experts' opinion is unlikely to be affected by stereotypes regarding creativity and creative people. This suggests that the Krasnoyarsk business community is capable of nurturing creativity in a working environment and is open to accepting creative people and outside-the-box thinkers whom it perceives as worthy partners.

The data from the third scale sheds light on the respondents' opinions regarding the role of new ideas in business. The results suggest that most business experts prefer activities connected with generating ideas and see them as playing a crucial part in allowing business to exist and develop.

The data from the fourth scale indicates how well the respondents manage to put their views in to practice. It reveals that the number of people uninterested in innovation and unable to think creatively is quite small compared with those who disagree that new ideas interfere with work or simply have no time to reviewand implement new ideas. That is, a small fraction of respondents see innovation as interference, whereas the majority try to find time and opportunity to make innovation happen.

Table 2. Results from surveying humanities students

\begin{tabular}{|c|c|c|c|c|c|}
\hline Scale \& Answers & $\begin{array}{c}\text { Completely } \\
\text { agree }\end{array}$ & $\begin{array}{c}\text { Rather } \\
\text { agree }\end{array}$ & $\begin{array}{l}\text { Not } \\
\text { sure }\end{array}$ & $\begin{array}{c}\text { Rather } \\
\text { disagree }\end{array}$ & $\begin{array}{c}\text { Completely } \\
\text { disagree }\end{array}$ \\
\hline Understanding the value of new ideas. & 26.9 & 32.2 & 15 & 14.6 & 7.2 \\
\hline Personal stereotypes regarding creativity & 9.6 & 14.6 & 17 & 34.6 & 20 \\
\hline Valuing new ideas for business & 34.5 & 36.5 & 19.25 & 4 & 1.7 \\
\hline Too busy for new ideas & 6.75 & 18.5 & 22.25 & 33.25 & 15.25 \\
\hline
\end{tabular}

Moststudent respondents, it appears, feel positive about the need to generate new ideas and see such ideas as valuable, worthy, and useful.On the whole, humanities students show a more clear-cutinclination towards understanding the importance of ideational thinking, compared with the Business Incubator experts, despite (or, perhaps, thanks to) not having to regularly evaluate new ideas as part of their job. It could be that business experts have developed a stricter and more skeptical attitude to innovative development as a result of being regularly involved in idea evaluation. 
Just like the Business Incubator experts, very few students tend to share the stereotypical view that creative people are disorganized and poorly adapted to the real world.Interestingly, compared to business experts, humanities students are more categorical in their belief that there should not be any stereotypical boundaries associated with creative people (such as being eccentric, disorganized, and so on). This might be because students have to delve in to the biographies of all kinds of creative and genius minds, who often turn out to have lived perfectly mundane and rational lives. Another noteworthy observation is that more humanities students than Business Incubator experts were 'not sure' about their answers in this category. Perhaps making up one's mind on this kind of issue requires a certain amount of liaison with creative people, butstudentsarestillintheprocessofaccumulatinglifeexperienceandsolidifying their views, which is why many of them still lack certainty in their opinions.

Most student respondents believe that new ideas are useful and prioritize activities aimed at generating ideas. In this regard, there is a clear consensus between Humanities students and the Business Incubator experts: both groups believe new ideas are vital for business.

The fourth scale overall suggests that students believe they are open to innovation: most of them claim they are able to work in this direction and make time and space for it. Percentage-wise, these findings are also in line with what the Business Incubator experts revealed with their responses.

\section{Concluding Remarks}

The results yielded by the study bring us to a number of conclusions regarding the attitude to innovation among business experts and humanities students. Comparative analysis revealed that both respondent groups have a fairly similar perspective on innovation. Most business experts appear to feel positive about innovation and innovatively inclined individuals.Business experts a real so open to working with creative people and ready to generate new ideas and put them into practice. They express only a small degree of skepticism regarding the unquestionable importance of ideating, which we believe might be attributed to their professional background.

Humanities students training for a degree in fields perceived as creative, but not vital for the country's innovation development, also appear to feel positive about innovation and ready to generate new ideas and put them into practice, just like the business community.

To sum up our findings, we can say that the Krasnoyarsk business community feels positive about innovation and is happy to implement it and welcome new creative thinkers. Humanities students from the Siberian Federal University also have a positive attitude to innovation and are themselves potential sources of new ideas, with a long-term prospect of joining the business community and putting innovation into practice.

\section{Acknowledgment}

The publications was prepared within the framework of the project Krasnoyarsk Krai Foundation for Support of Scientific and Technical Activity.

\section{References}

Ahuja, G. (2000). Collaboration networks, structural holes, and innovation: A longitudinal study. Administrative science quarterly, 45(3), $425-455$

Anoshkina, V.L., \& Rezvanov, S.V. (2001). An Education. Innovation. The Future. Russia, Rostov-on-Don: PO IPK and missile defense.

Baer, M. \& Oldham, G. R. (2006). The curvilinear relation between experienced creative time pressure and creativity: moderating effects of openness to experience and support for creativity. Journal of Applied Psychology, 91(4), 963.

Bain, P. G., Mann, L. \& Pirola-Merlo, A. (2001). The Innovation Imperative The Relationships Between Team Climate, Innovation, and Performance in Research and Development Teams. Small Group Research, 32(1), 55-73.

Basadur, M. \& Hausdorf, P. (1996). Measuring Divergent Thinking Attitudes Related to Creative Problem Solving and Innovation Management. Creativity Research Journal, 9 (1), 21-32.

Bogomaz, S.A. \& Nepomnyaschaya, V.A. (2007). On the problem of searching the psychological bases of development of innovative components of personality in adolescence and youth. Siberian psychological journal, 25, 78-82.

Culture Matters: How Values Shape Human Progress. (2000). Ed. by L. E. Harrison and S. P. Huntington. New York.

Dolgov, V.I. (2013). Psychophysiological determinants of willingness to innovate. Bulletin of Chelyabinsk State Pedagogical University, 12.

Dollinger, S. J., Burke, Ph. A. \& Gump, N. W. (2007). Creativity and Values. Creativity Research Journal, 19(2-3), 91-103.

Drejer, I. (2004). Identifying innovation in surveys of services: a Schumpeterian perspective. Research Policy, 33(3), 551.

Garcia, R. \& Calantone, R. (2002). A critical look at technological innovation typology and innovativeness terminology: a literature 
review. Journal of Product Innovation Management, 19(2), 110-132.

Goldsmith, R. E. (1984). Personality characteristics associated with adaption-innovation. The Journal of psychology, 117(2), $159-165$.

Glor, Eleanor D. (2015). Building Theory of Organizational Innovation, Change, Fitness and Survival. TIJ, 20 (2). Accessed May 20 , 2015 at http://www.innovation.cc/books/20_2_1a_glor_fit_organizations.pdf

Glor, Eleanor D. (2015). Review Essay of New Directions in Saskatchewan Public Policy and Remaining Loyal: Social Democracy in Quebec and Saskatchewan by David P. McGrane. The Innovation Journal: The Public Sector Innovation Journal, Volume 20 (1), article 7. Accessed May 20, 2015 at http://www.innovation.cc/book-reviews/20_1_7_glor_rev-essy_mc-grane.pdf

Goldsmith, R. E. \& Hofacker, C. F. 1991. Measuring Consumer Innovativeness. Journal of the Academy of Marketing Science, 19(3), 209-221.

Hauser, J., Tellis, G. J. \& Griffin, A. 2006. Research on Innovation: A Review and Agenda for Marketing Science. Marketing Science, 25(6), 687-717.

Ilbeykina, M. I., Kolesnik, M. A., Libakova, N. M., Sertakova, E. A., \& Sitnikova, A. A. (2015). Global and Local Trends in Development of the Siberian City of Krasnoyarsk. Mediterranean Journal of Social Sciences, 6(3 S5), 241-248.

Jansen, J. J. P., Van Den Bosch, F. A. J. \& Volberda, H. W. 2006. Exploratory Innovation, Exploitative Innovation, and Performance: Effects of Organizational Antecedents and Environmental Moderators, Management Science, 52(11), 1661-1674.

Janssen, O., Van de Vliert, E. \& West, M. (2004). The bright and dark sides of individual and group innovation: A special issue introduction. Journal of Organizational Behavior, 25(2), 129-145.

Kharkhurin, A. \& Motalleebi, S. N. S. (2008). The Impact of the Creative Potential of American, Russian, and Iranian College Students. Creativity Research Journal, 20(4), 404-411.

Kirko, V.I., Beloshapkin, V.V. \& Belova, E.N. (2013). Innovative Development of Krasnoyarsk Region Territories on the Basis of Serive Centers Net of Kspu Named After V.P. Astavyev is a Possibility for Business-Model "Triple Spiral" by G. Etzkowitz Realization. Journal of Siberian Federal University. Humanities \& Social Sciences, 10 (6), 1507-1513.

Kirko, V.I., Popodko, G.I. \& Goloushkin, R.D. (2012). The Mechanism of Implementing the Business Model of Open Innovation for the Involvement of Potential of a Closed City in the Innovative Development of the Region. Journal of Siberian Federal University. Humanities \& Social Sciences, 7 (5), 978-987.

Kirton, M. (1976). Adaptors and Innovators: A Description and Measure. Journal of Applied Psychology, 61 (5), 622-629.

Kirton, M. J., \& De Ciantis, S. M. (1986). Cognitive style and personality: The Kirton adaption-innovation and Cattell's sixteen personality factor inventories.Personality and Individual Differences, 7(2), 141-146.

Kistova, A.V., Pimenova, N.N., Zamaraeva, Ju.S., \& Reznikova, K.V. (2014). Research possibilities for studying the indicators of quality of life of indigenous peoples of the North (based on the study of indigenous peoples of the North of Russia). Life Sci J, 11(6s), 593-600.

Klochko, V.E., \& Galazhinsky, E.V. (2009). The innovative potential of the individual: a systematic anthropological context. Bulletin of Tomsk State University, 325.

Koptseva, N. (2014). Expert analysis of the main trends of Northern Siberia's Indigenous small-numbered peoples economic development. Economic Annals-XXI, 11-12, 93-96.

Koptseva, N.P. ,\& and Kirko, V.I. (2014a). The information basis for formation of positive ethnic identities in the process of acculturation of indigenous peoples of the Arctic Siberia (Krasnoyarsk, Russia). Life Sci J, 11(8), 479-483.

Koptseva, N.P., \& Kirko, V.I. (2014b). Modern specificity of legal regulation of Cultural Development of the Indigenous Peoples of the Arctic Siberia under the global transformations. Life Sci J, 11 (9), 314-319.

Kurylenko, L. 2001. Theory and practice of individual development actors of the educational process of innovative educational institutions: dis ....Dr. ped. Sciences.

Lebedeva, N.M. (2008). Cultural values, economic attitudes and attitudes to innovation in Russia. Psychology. Journal of Higher School of Economics, 5 (2), 68-88.

Lebedeva, N.M. (2009). Values and attitudes towards innovation: cross-cultural differences. Psychological Journal, 30 (6), $81-92$.

Lebedeva, N.M. (2011). Socio-cultural factors of creativity and innovation: a cross-cultural approach. China, 41 (49), 5.

Lebedeva, N.M. \& Tatarko, A. (2009). Technique to study the relationship of the individual to innovate. Almanac of modern science and education. Tambov: Diploma, (4), 23.

Lenskaya, E. (2014). Nine successful Projects: why we Cannot Draw Lessons from our Own Experience. Journal of Siberian Federal University. Humanities \& Social Sciences, 12 (7), 2133-2142.

Libakova, N.M, Sitnikova, A.A., Sertakova, E.A., Kolesnik, M.A.. \& Ilbeykina, M.I. (2014). Interaction of the Yakut ethnicity and biological systems in the territory of the Sakha Republic (Hordogoy settlement, Suntarsky District) and Krasnoyarsk Krai (Essey settlement, Evenks District). Life Sci J, 11(6s), 585-592.

Lin, H. F. (2007). Knowledge sharing and firm innovation capability: an empirical study. International Journal of Manpower, 28(3/4), 315332.

Miron, E., Erez, M. and Naveh, E. (2004). Do personal characteristics and cultural values that promote innovation, quality, and efficiency compete or complement each other? Journal of organizational behavior, 25(2), 175-199.

Moskvich, Y.N. \& Victoruk, E.N. (2011). Values of Innovation for Students, Experts and Entrepreneurs in Krasnoyarsk: Desired Ideal, Hopes and Reality. Journal of Siberian Federal University. Humanities \& Social Sciences, 11 (4), 1507-1525.

Moskvin, S. (2008). Formation of Integrating Mechanisms of Science-Intensive Enterprise Management in the Conditions of Knowledge Economy. Journal of Siberian Federal University. Humanities \& Social Sciences, 3 (1), 354-360. 
Prajogo, D. I. (2006). The relationship between innovation and business performance-a comparative study between manufacturing and service firms. Knowledge and process management, 13(3), 218-225.

Ruppel, C. P. and Harrington, S. J. (2000). The relationship of communication, ethical work climate, and trust to commitment and innovation. Journal of business Ethics, 25(4), 313-328.

Sawhney, M., Wolcott, R. C. \& Arroniz, I. (2006). The 12 Different Ways for Companies to Innovate. MIT Sloan Management Review, 47(3): 75-81.

Schwartz, S. H. (2006). Basic human values: Theory, measurement, and applications. Revue.

Shane, S., Venkatarman, S. \& Mac-Millan, I. (1995). Cultural Differences in Innovation Strategies. Journal of Management, 21(5), 931952.

Sevastyanova, A.E. (2015). Approach to Justification of Innovation Policy for Raw-material Regions. Journal of Siberian Federal University. Humanities \& Social Sciences, Supplement, (8), 98-107.

Smith, P., Peterson, M., \& Schwartz, S. (2002). Cultural Values, Sources of Guidance and Their Relevance to Managerial Behavior. Journal of Cross-Cultural Psychology, 33(2), 188-208.

Sood, A. and Tellis, G. J. (2005). Technological Evolution and Radical Innovation. Journal of Marketing, 69(3), 152-168.

Sovetova, O.S. (2000). Basics of social psychology of innovation: the manual. Russia, St. Petersburg: Publishing house of St. Petersburg State University.

Steel, G. D., Rinne, T. and Fairweather, J. (2012). Personality, nations, and innovation: Relationships between personality traits and national innovation scores. Cross-Cultural Research, 46(1), 3-30.

Teece, D. J. (1996). Firm organization, industrial structure, and technological innovation. Journal of Economic Behavior \& Organization, 31(2), 192.

Van de Ven, A .H. (1986). Central Problems in the Management of Innovation. Management Science, 32(5), 590-607.

Volobueva, N.M. (2012). Innovative quality of young people with different levels of resilience of the individual. The Man. The Community. The Management, 4, $39-44$.

Wu, C. H., Parker, S. K., \& De Jong, J. P. (2014). Need for cognition as an antecedent of individual innovation behavior. Journal of Management, 40(6), 1511-1534.

Zamarayeva, Y. S., Kistova, A. V., Pimenova, N. N., Reznikova, K. V., \& Seredkina, N. N. (2015). Taymyr Reindeer Herding as a Branch of the Economy and a Fundamental Social Identification Practice for Indigenous Peoples of the Siberian Arctic. Mediterranean Journal of Social Sciences, 6(3 S5), 225.

Zhang, Y. (2015). Analysis on the Path of the Innovation of the Cultural Quality-Oriented Education in University. Creative Education, 6(03), 415.

Zibarras, L. D., Port, R. L. and Woods, S. A. (2008). Innovation and the 'Dark Side'of Personality: Dysfunctional Traits and their Relation to Self-Reported Innovative Characteristics. The Journal of Creative Behavior, 42(3), 201-215. 